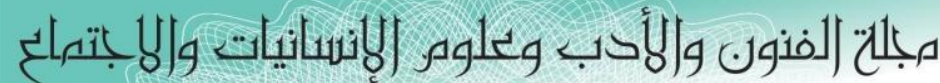

Journal of Arts, Literature, Humanities and Social Sciences

ISSN online: 2414 - 3383

ISSN print: 2616 - 3810

العدد (43) ايلول - سبتمبر 2019

\title{
تمثلات التقد التحليلي في كتب أخبار الشعراء
}

\author{
أ.د. مزاحم مطر حسين

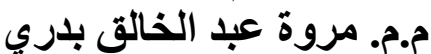 \\ جامعة القادية ـ كلية التربية ـ قسم اللغة العربية \\ العراق التربة
}

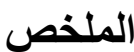

يمثل النقد التحليلي مرحلة منطورة قياساً بالنقد الانطباعي، وكذلك النقد اللغوي؛ ذلك لأن الناقد يُعمل العقل في

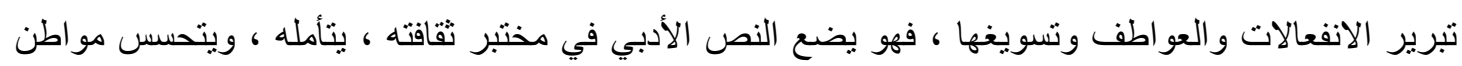
جماله أو قبحه، ثم يدرس ما يحتويه من خصائص، ويكثف عما فيه من معان وقيم متكئاً على ما يتكئ عليه النقد

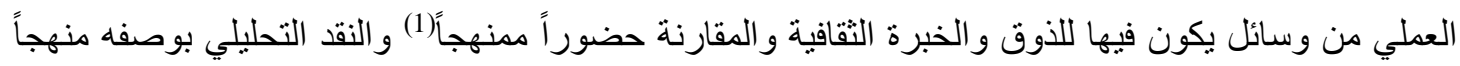

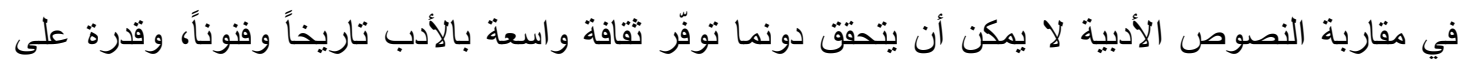

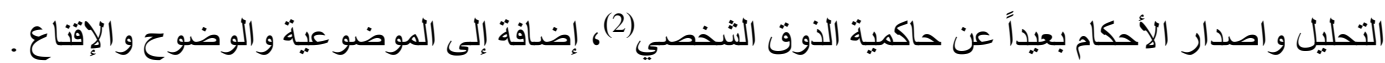
وفي مدونات أخبار الثعراء شغل هذا الضرب من النقد مساحة واسعة في بعضها وتضاءل حضوره في بعضها الآخر، فقد شكَّل حضوراً لافتاً للنظر في (اخبار ابي تمام)، و(اخبار البحتري)، (اخبار الثعراء

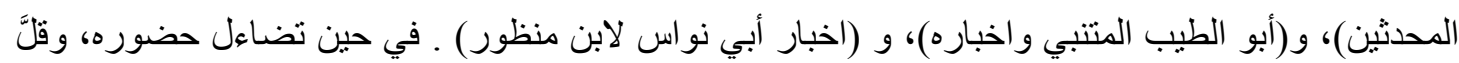

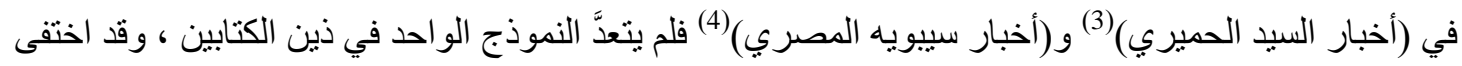

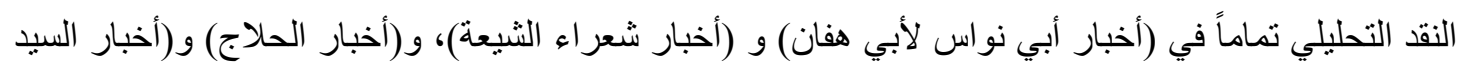
الحميري)، و(نزهة المسامر في أخبار مجنون بني عامر)، فلم ترد أخبار في هذه المدونات تحمل منطلقات النقد

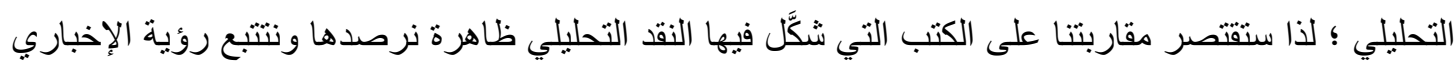
في رواية الأخبار ذات النزوع التحليلي، محاولين أن نقف على طبيعة التحليل النقدي منهجاً ورؤيةً تحليليةً . 


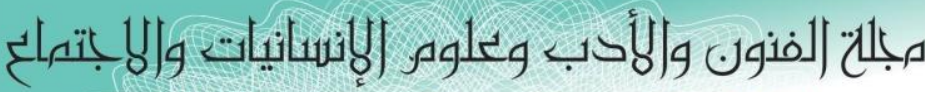

Journal of Arts, Literature, Humanities and Social Sciences

ISSN online: 2414 - 3383

ISSN print: 2616 - 3810

أيلول -سبتهبر 2019

العدد (43)

\title{
Examples of Analytical Criticism in Poets' News Books
}

\begin{abstract}
Analytical criticism represents an advanced stage in comparison with Impressionist criticism, as well as linguistic criticism, because the critic works the mind in justifying and justifying emotions and emotions. Analytical criticism as an approach to literary texts cannot be achieved without a broad culture of literature, history and arts, and the ability to analyze and make judgments away from the ruler. in addition to objectivity, clarity and persuasion.

In the books of poets news this kind of criticism occupied a large area in some of them and diminished his presence in others, it constituted a remarkable presence in (Akhbar Abu Tammam), (Akhbar Albohtari), (Akhbar Alsora Almohdtheen), (Abu Altayeb al-Mutanabbi wa Akhbaoaho), And (Akhbar of Abu Nawas). While his presence dwindled, and said in (Akhbar Sayyid al-Humayri) and (Akhbar Siboih Almasri) did not exceed the one model in those books, has disappeared analytical criticism completely (Akhbar Abu Nawas) and (Akhbar Alshoara Alsheea), There is no news in these blogs carrying the starting points of analytical criticism, so our approach will be limited to books where analytical criticism was a phenomenon we monitor and follow the news vision in Analytical news story, trying to see the nature of critical analysis as an analytical approach.
\end{abstract}




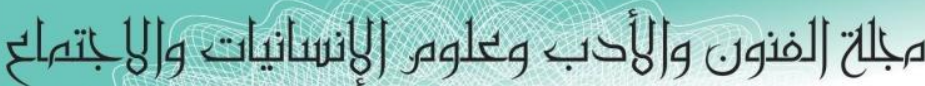

Journal of Arts, Literature, Humanities and Social Sciences

ISSN online: 2414 - 3383

ISSN print: 2616 - 3810

\section{العدد (43) ايلول - سبتمبر 2019}

أولاً : الصولي : من تجهيل الخصوم إلى الاحتفاء بالمحدثين النظر للأحكام النقدية ذات النزوع التحليلي في كتب الصولي التئي الثلاثة (أخبار أبي تمام) و( أخبار البحتري)

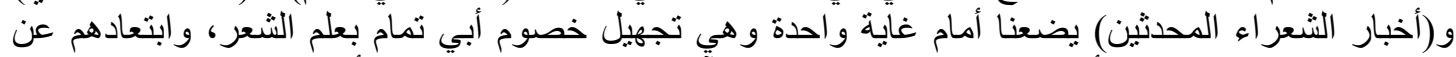

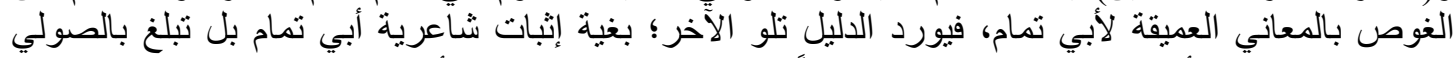

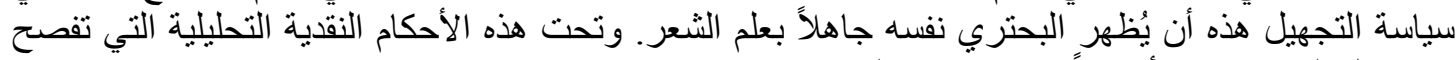

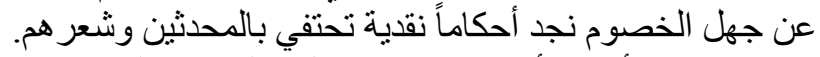

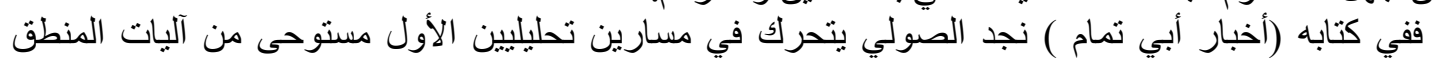

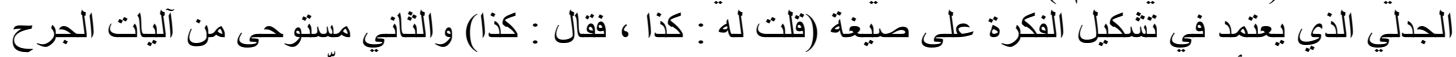

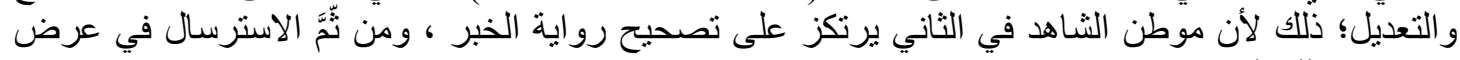

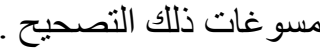

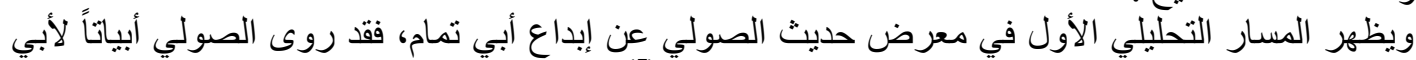

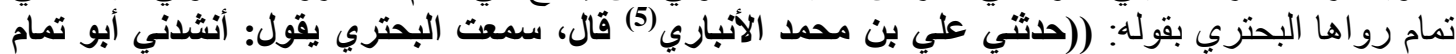

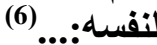

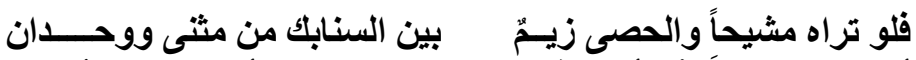

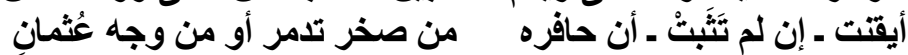

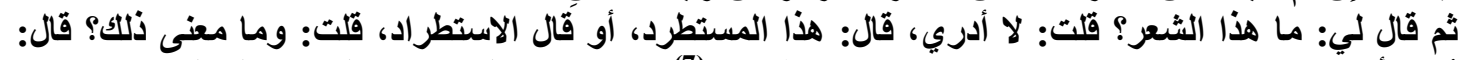

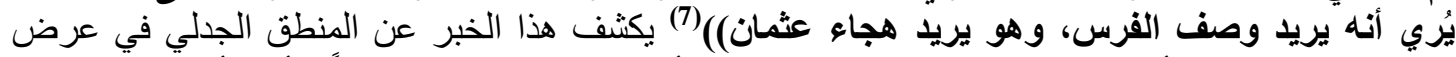
الفكرة، ونستشف منه أن البحتري كان يعرف الاستطر اد، وأن الاستطر اد لم يكن شائعاً؛ لأن الأنباري قُّ تساءل

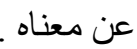

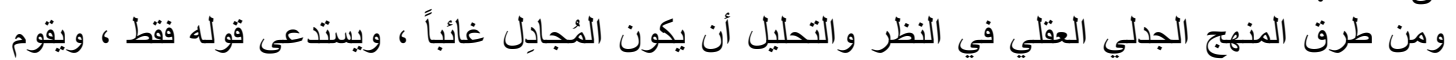

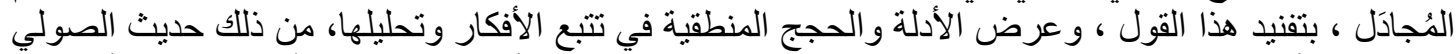

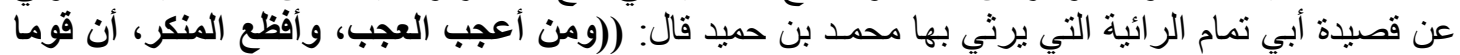

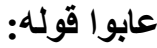

كأن بني نبهان يوم وفاته

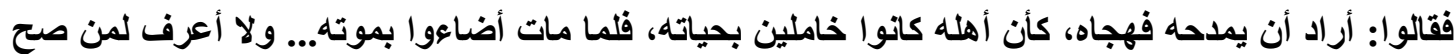

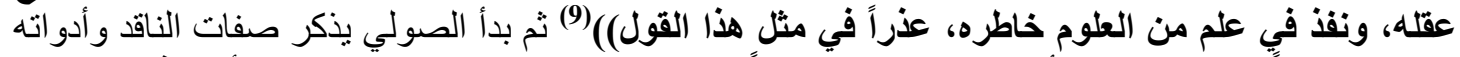

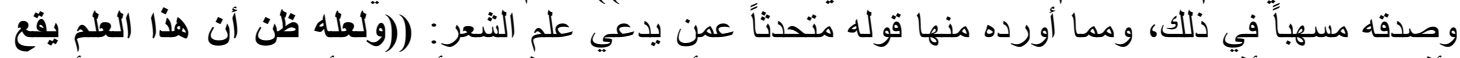

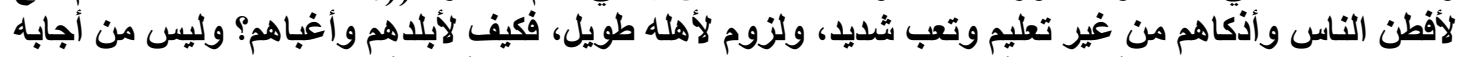

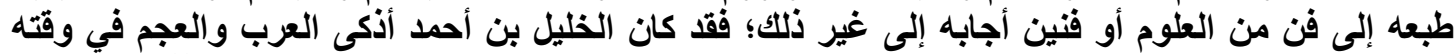

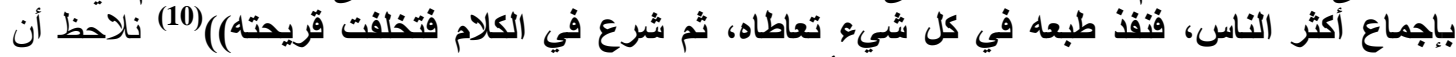

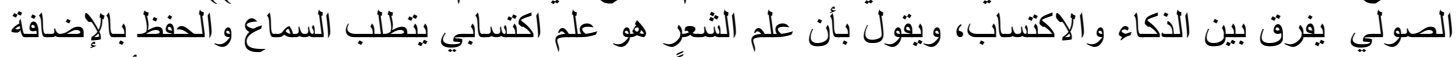

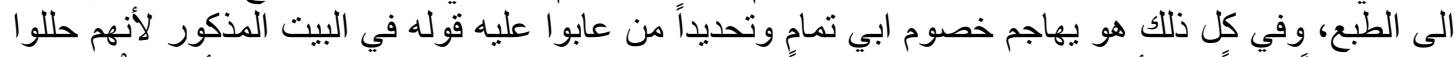

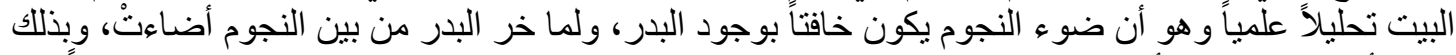

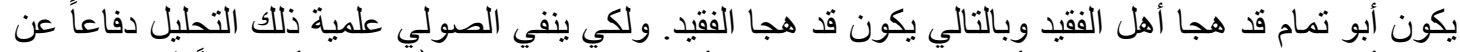

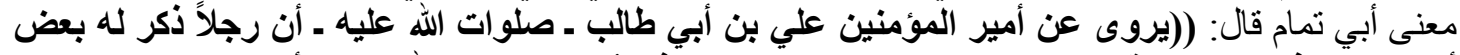

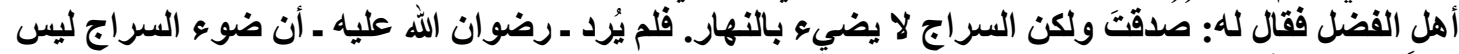

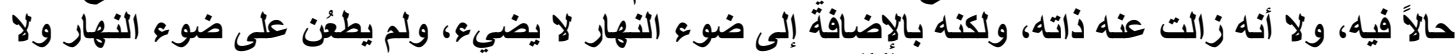

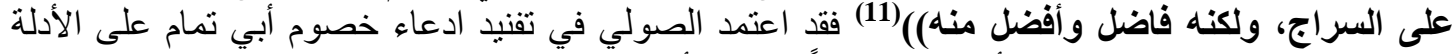

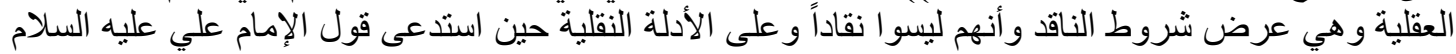

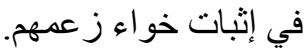




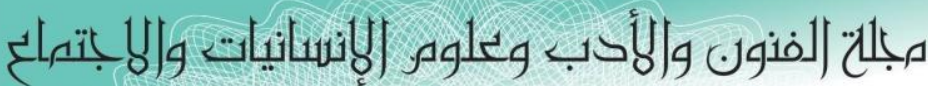

Journal of Arts, Literature, Humanities and Social Sciences

ISSN online: 2414 - 3383

ISSN print: 2616 - 3810

أيلول -سبتمبر 2019

العدد (43)

أما على صعيد المسار التحليلي الثاني وهو تصحيح رواية البيت ومن ثم تعليل الرواية الثانية بأوجه عدة، فمن

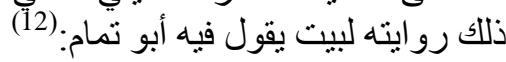

لهفي على تلك المخاتل فيهمـا لو أُمهلت حتى تكون شمائلا

لذا سكونهما حجى وصباهما كرما وتلك الأريحية نائســلا

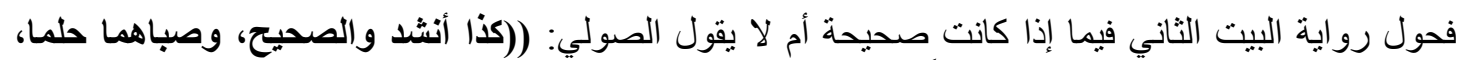

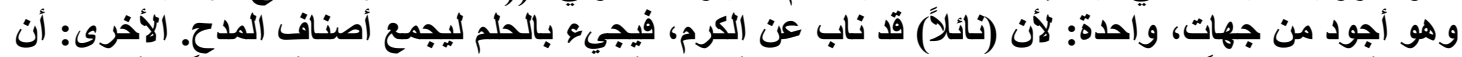

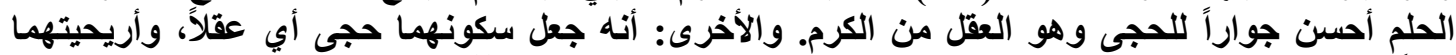

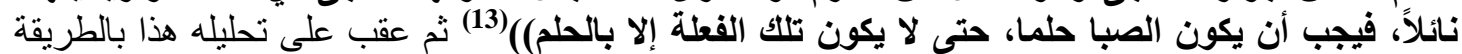

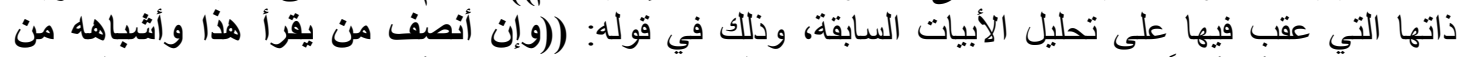

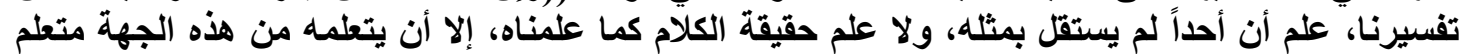

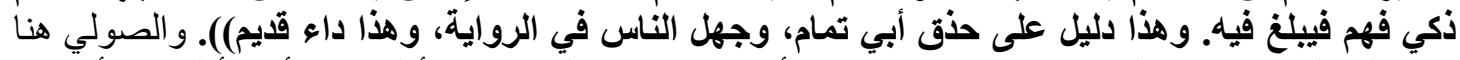

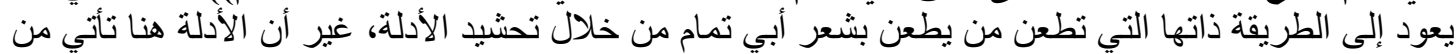

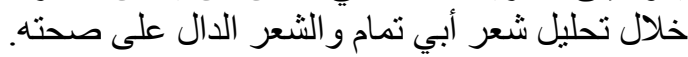

ويمكن أن نضيف مسار اً نالثاً وهو الاستئناس بالتحليل ومحاولة إثبات صحة طبع أبي تمام في الثعر ، إذ نقر أ في هذا الصدد تحليلاً للصولي لبيتين لم يذكر قائلهما هما قول الثناعر :(14)

أصفراء كان الود منك مباحسـ ليالي كان الهجر منك مزاحس

وكن جواري الحي إذ كنت فيهم قباحاً، فلما غبت صرن ملاحا

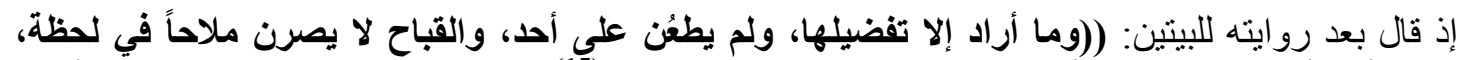

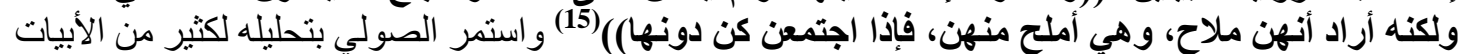

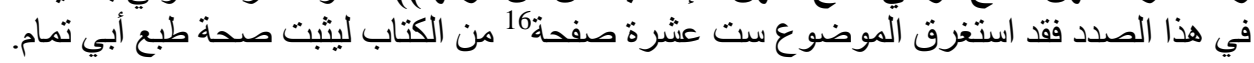

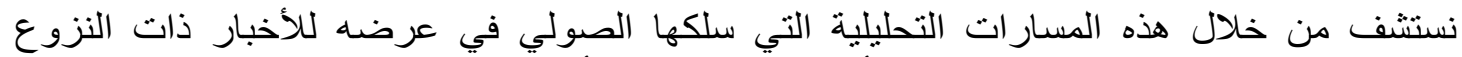

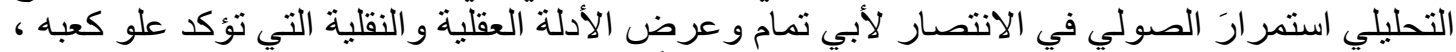

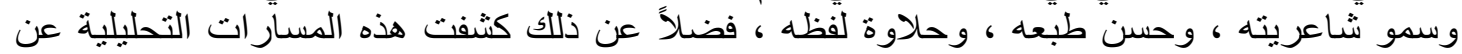

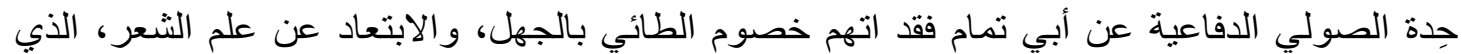
يمكنهم من التوص في عو المه الخلاقة.

وفي كتابه (أخبار البحتري) يعتمد الصولي على الإيجاز و التكثيف في إيراد الأخبار ذات النزوع التحليلي، فقا

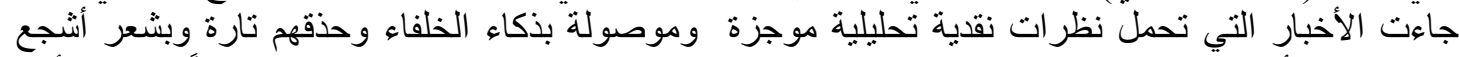

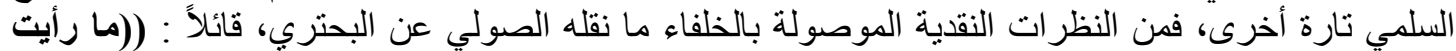

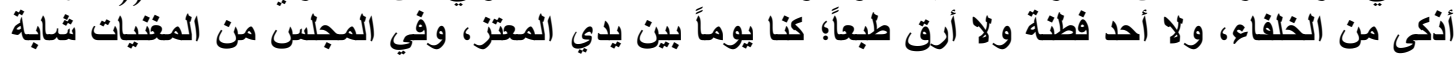


مجلحت (لفنون والأدب وتلوه الإنسانيات والبانتهاع

Journal of Arts, Literature, Humanities and Social Sciences

ISSN online: 2414 - 3383

ISSN print: 2616 - 3810

أيلول - سبتمبر 2019

العدد (43)

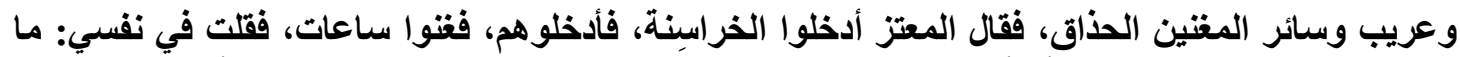

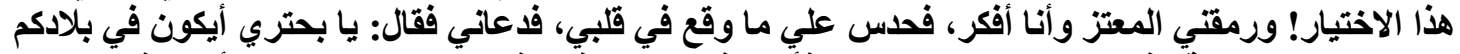

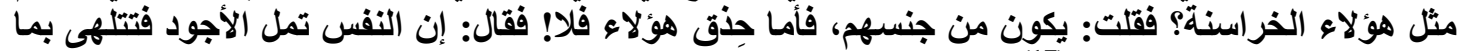

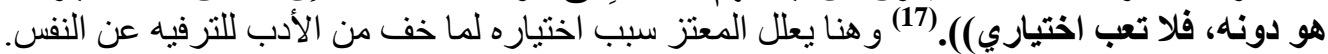

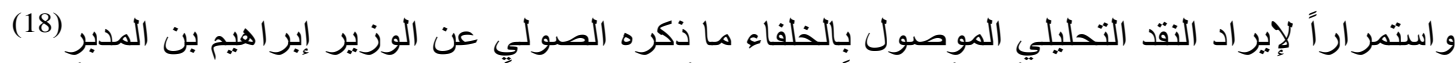

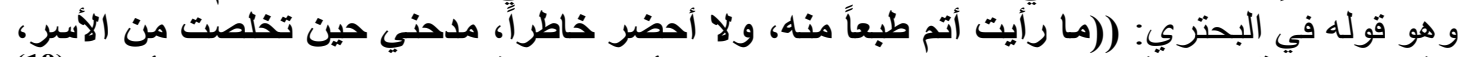

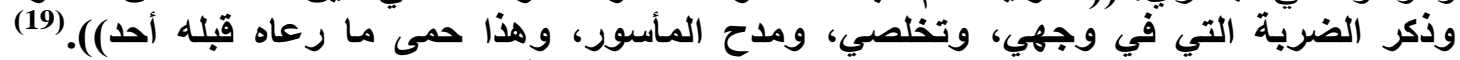
و وإبر اهيم بن المدبر هنا يتحدث عن قصي، وتيدة الّبحتري التي يقول في أولها:

\section{قد كان طيفك مرة يغري بي يعتاد ركبي طارقاً وركابي(20)}

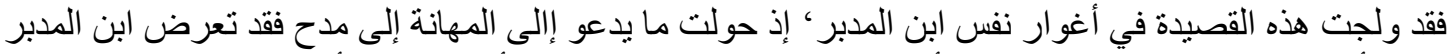

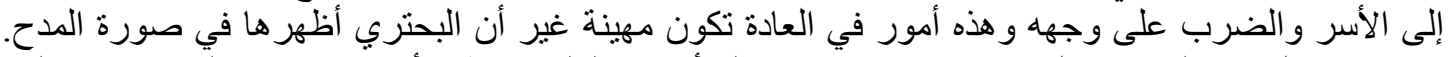

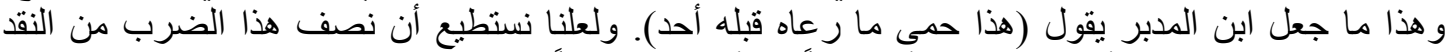

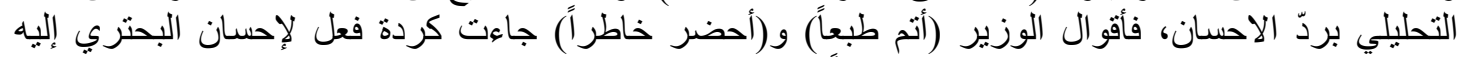

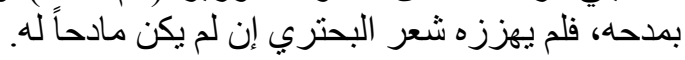

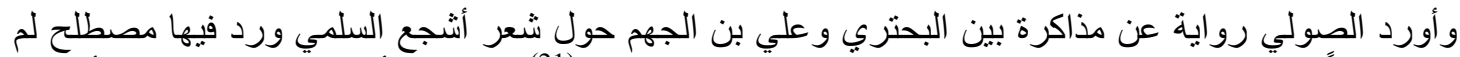

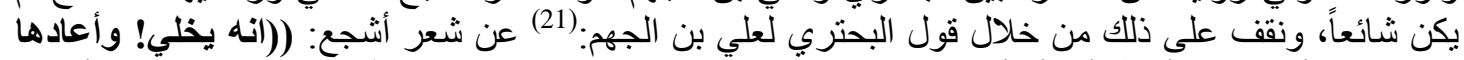

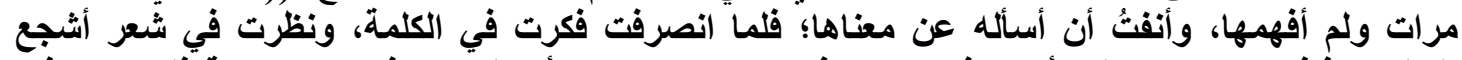

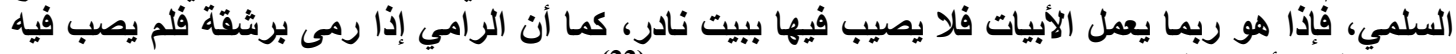

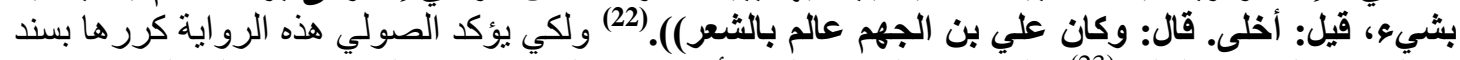
مختلف في الصفحة التالية.

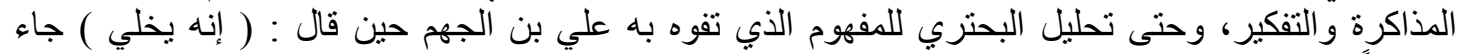

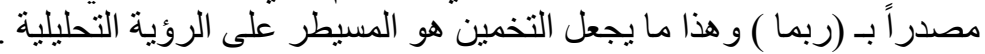

من خلال ما تقدم يمكن إيجاز ستر اتيجة الصولي في عرض الأخبار ذات النزوع التحليلي في كتابه (أخبار البحتر

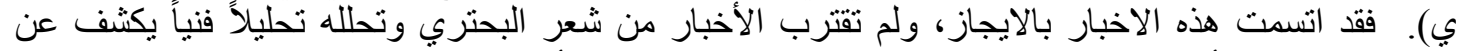

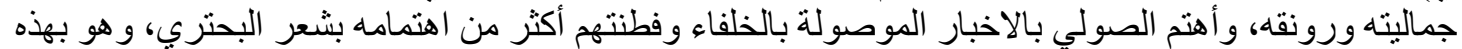
الستر اتيجية يو اصل السير صوب تقويض بض شاعرية البحتري ، وتجريده حتى من العلم بالشعر.

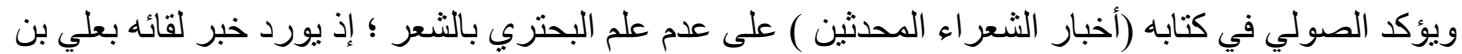

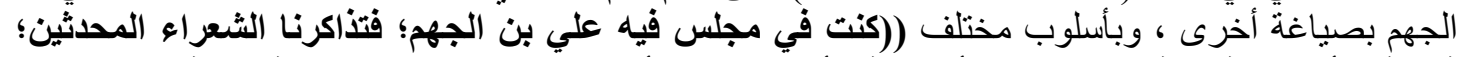

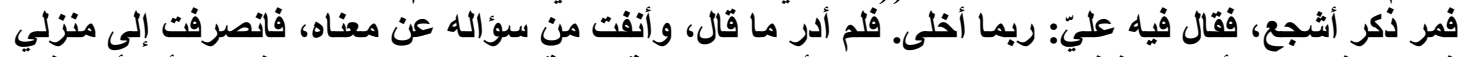

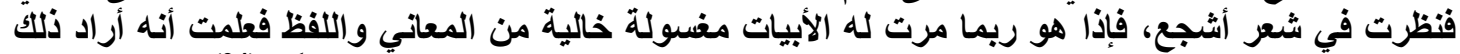

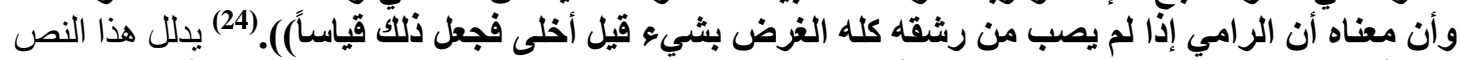

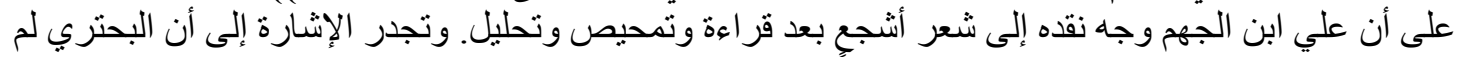
يقل (فاستعار الإخلاء) بل فال: (فجعل ذللك قياسا). 


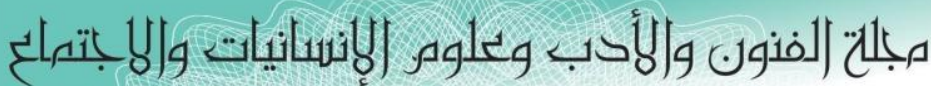

Journal of Arts, Literature, Humanities and Social Sciences

ISSN online: 2414 - 3383

ISSN print: 2616 - 3810

\section{العدد (43) ايلول - سبتمبر 2019}

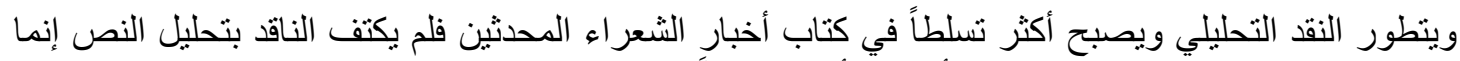

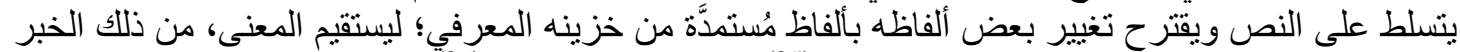

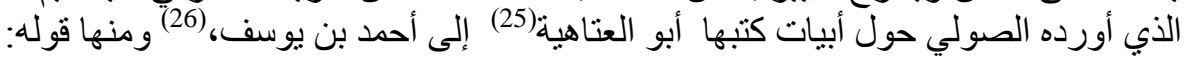

ألم تز أن الفقر يرجى له الغنى وأن الغنى يخشى عليه من الفقر (27)

وفيثير سمع ذللك علي بن جبلة(28) قال: ((بئسما صنع كان ينبغي له أن يقول له: ألحمد أن الفقر يرجى له الغنى

يتبين مما سبق أن الأخبار ذات النزوع التحليلي (30) الني جاءت في كتاب أخبار الثعر اء المحدثين كانت كاثنفة

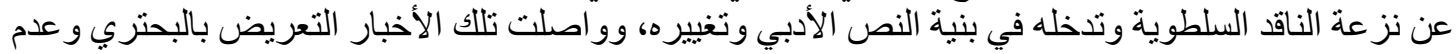

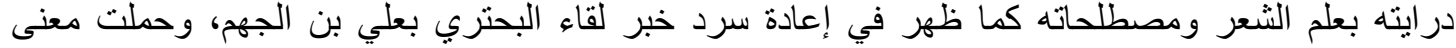
التعريض بشعر الثاعر.

ثانياً : الثعالبي : قُبح المطالع وحُسن القصيد.

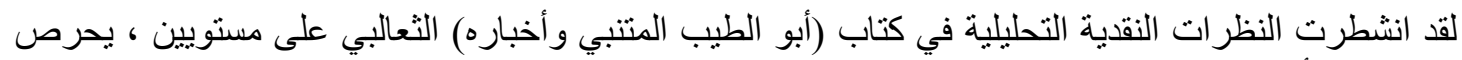

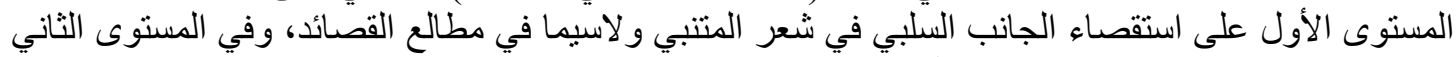

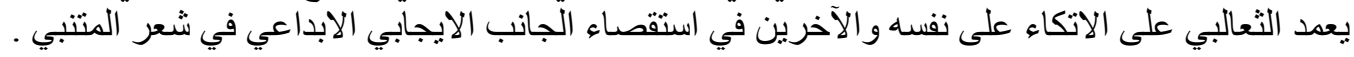

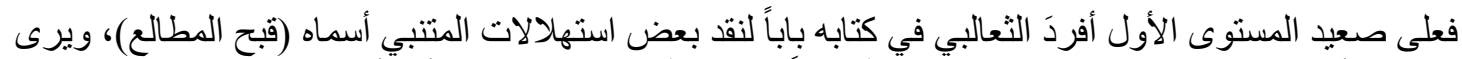

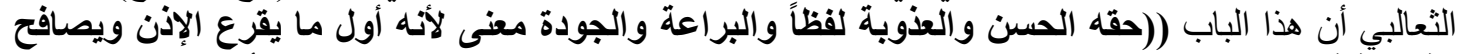

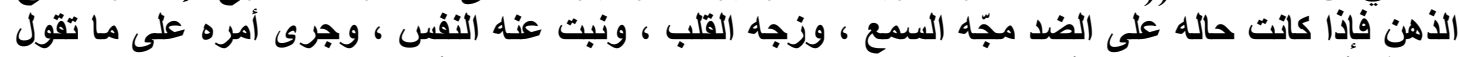

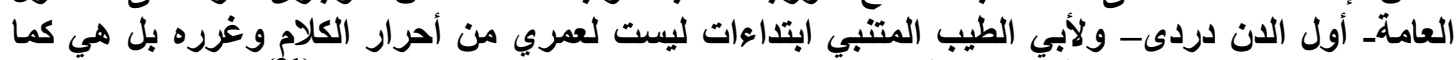

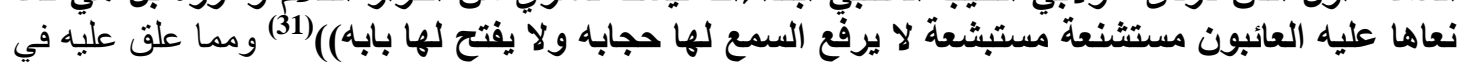

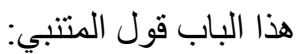

هذي برزتِ لنا فهجتِ رسيسا ثم انصرفتِ وما شَفَيتِ نسيسا(32)

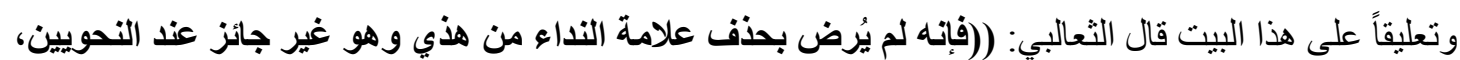

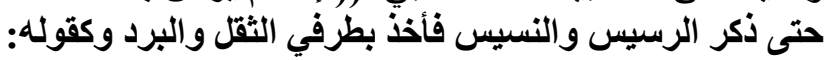

(أوّه بديل من قولتي واها)(33) (2)

وهو برقية العقرب أثبه منه بافتتاح كلام في مخاطبة ملك)). (34) الملاحظ على تحليل الثعالبي لهذا المطلع انه الهابه

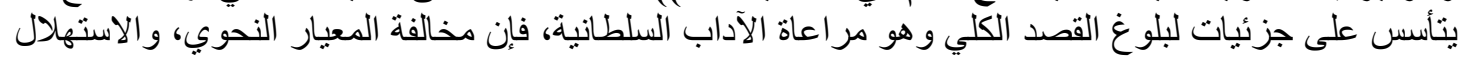
الذي يأخذ بطرفي البرد و الثقل لا يحقان في مخاطبة الملوك. 


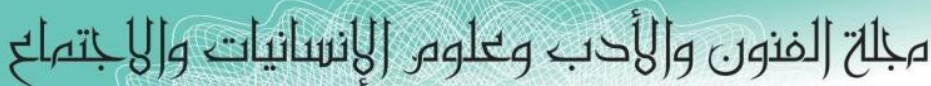

Journal of Arts, Literature, Humanities and Social Sciences

ISSN online: 2414 - 3383

ISSN print: 2616 - 3810

العدد (43) ايلول -سبتمبر 2019

وتتأسس بعض تحليلات الثعالبي على الجانب البلاغي و لاسيما في البحث عن الملاءمة بين اللألفاظو الابتعاد عن

التكلف و التعقيد و الغرابة، من ذلك موقفه من مطلع قصيدة المتنبي التي يقول فيها:

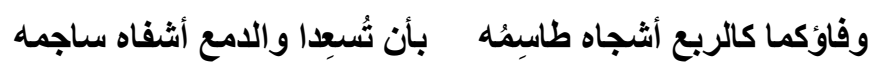

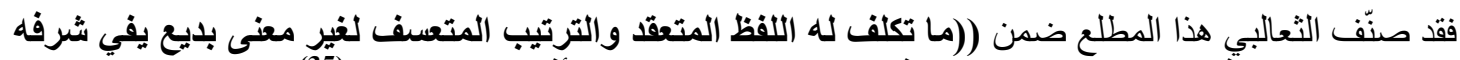

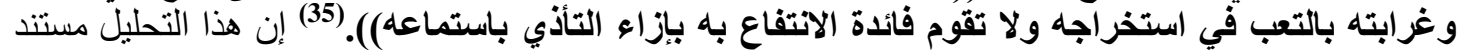

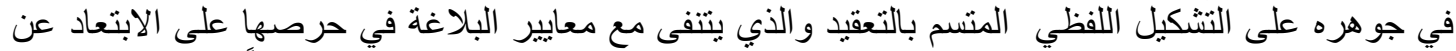
التعقيد ونبذ التكلف ، وهجر الغرابة، في إثنارة إلى إمكانية قبول ذلّك فيما إذا كان المعنى شريفاً.

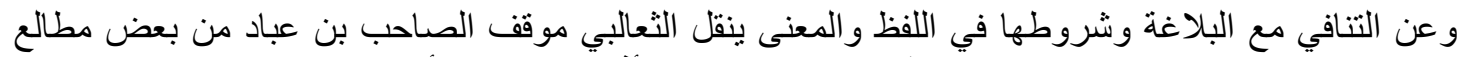

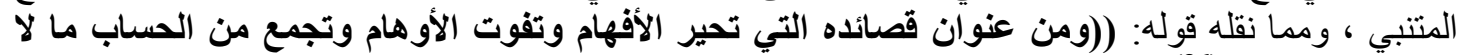

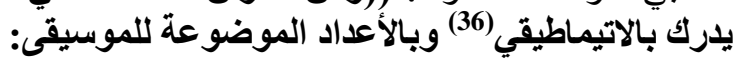

أحاد أم سداد في أحاد لليلتنا المنوطة بالتنادي(37)

و هذا كلام الحكل (38) ورطانة الزط(39) وما ظنك بممدوح قد تثمر للسماع من مادحه فصك سمعه بهذه الألفاظ

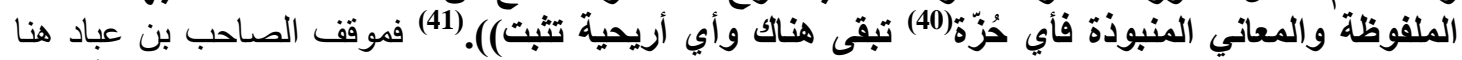

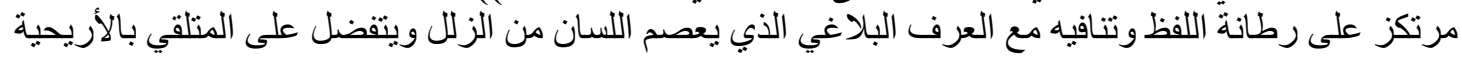
و والالتذاذ.

وينقل الثعالبي عن الصاحب بن عباد موقفه الاستنكاري من مطالع المتنبي وينعتها بالعجيبة إذ يقول : (ومن التهن افتتاحاته العجيبة قوله لسيف الدولة في التسلية عند المصيبة:

لا يحزن الله الأمير فإنني لآخذ من حالاته بنصيب(42)

قال الصاحب: لا أدري لمَ يحزن سيف الدولة إذا أخذ المتنبي بنصيب من القلق)(43) السؤال

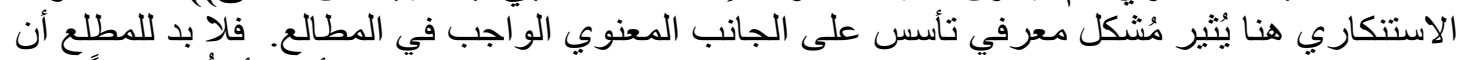

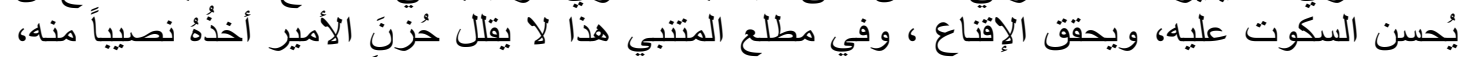

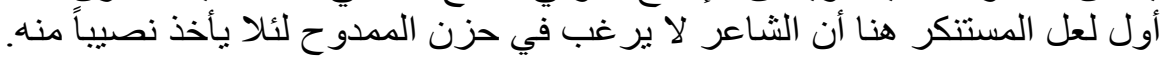

وينقل الثنعالبي أخبار أ عن الأثر الذي يتركه المطلع في النفس وهو هنا يركز على الجانب المعنوي في التحليل من ذللك موقفه من مطلع المتنبي الذي يقول فئه الذيه :

كفى بك داء أن ترى الموت شافيا وحسب المنايا أن يكن أمانيــــــ(44)

فقد علق الثعالبي على هذا البيت بقوله: ((وفي الابتداء بذكر الداء والموت والمنايا ما فيه من الطيرة التي تنفر

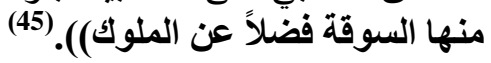




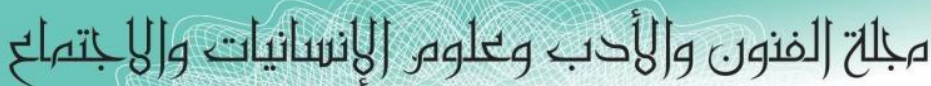

Journal of Arts, Literature, Humanities and Social Sciences

ISSN online: 2414 - 3383

ISSN print: 2616 - 3810

أيلول - سبتمبر 2019

العدد (43)

ولكي يسند الثعالبي رأيه في أهمية التفاؤل في المطلع نقل عن الصاحب بن عباد ما قاله ابن مقاتل في يوم عيد:

لا تقل بشرى ولكن بشريان غرة الداعي ويوم المهرجــان (46)

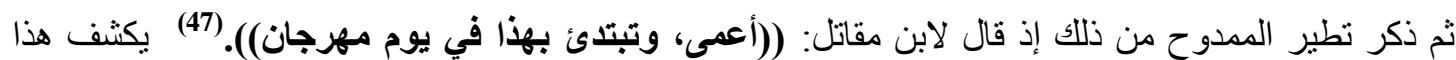

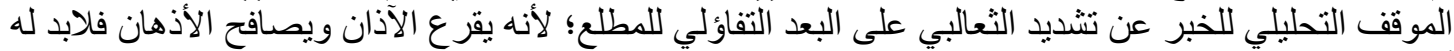
أن يحمل في طياته التفاؤل ويبتعد عما يُنطيَّر منه.

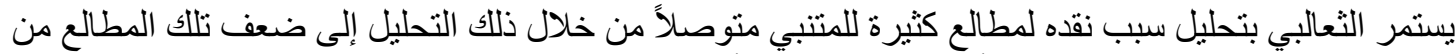

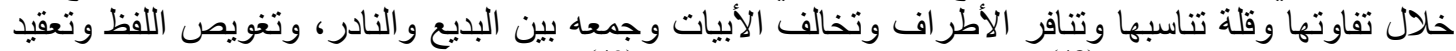

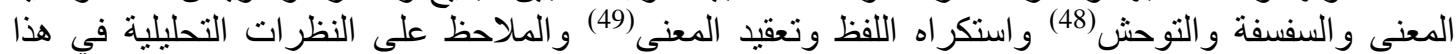

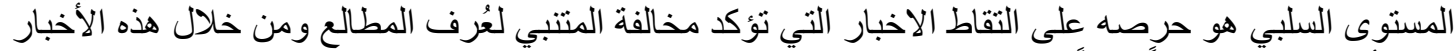

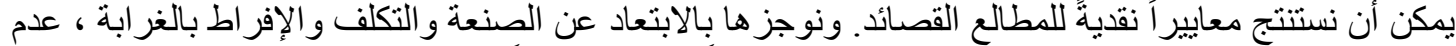

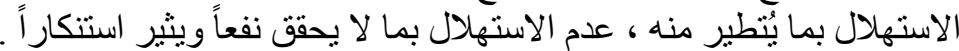

وفي المستوى الثاني من الاحكام النقدية التحليلية يُظهر الثعالبي البراعة الثعرية لأبي الطيب المتنبي، مستعيناً

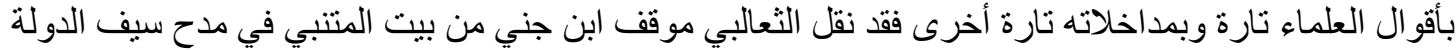

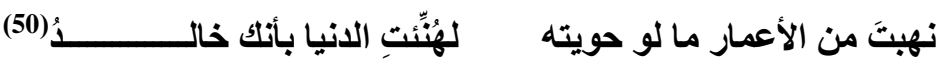

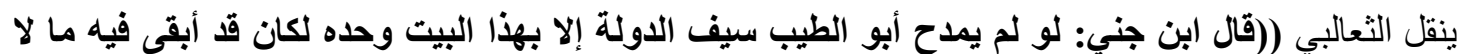

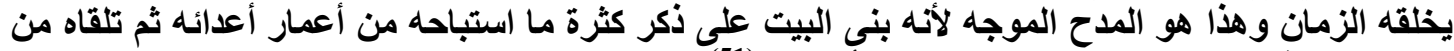

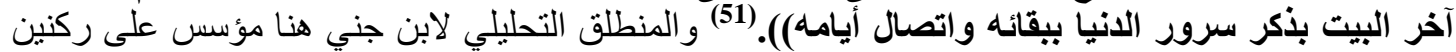

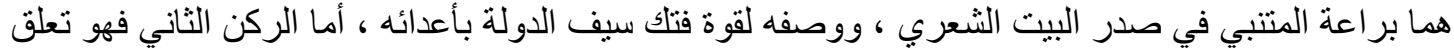

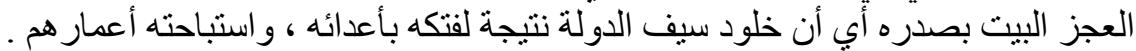

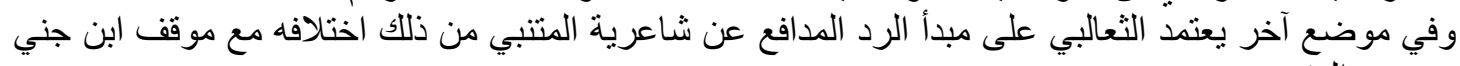

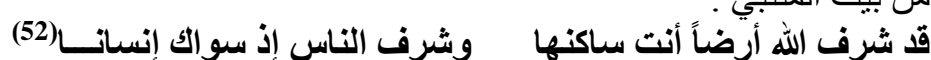

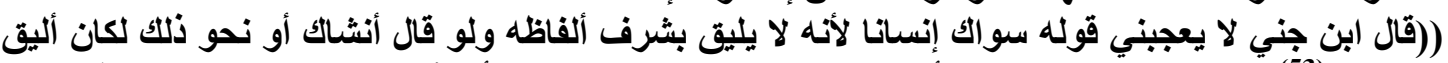

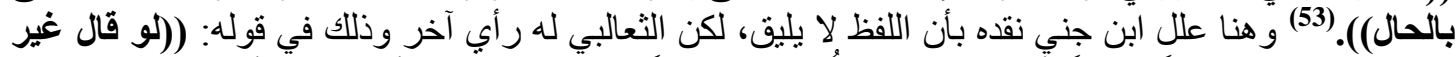

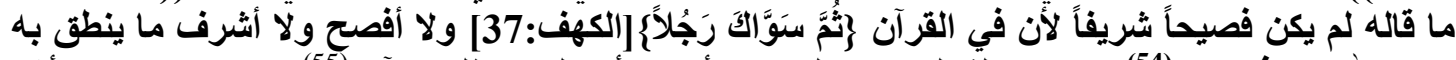

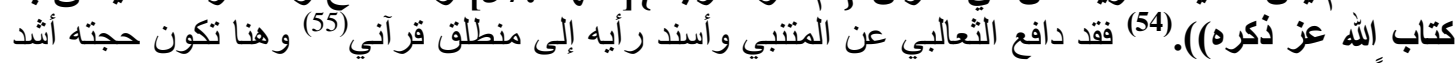
بر هاناً من حجة ابن جني.

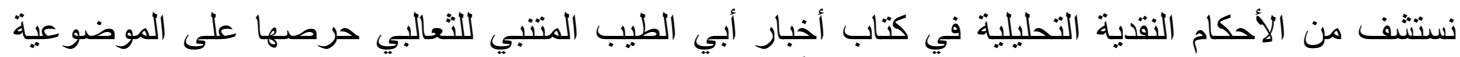

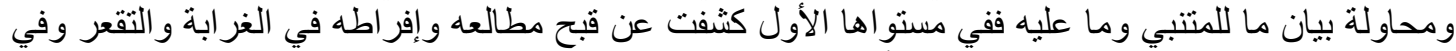

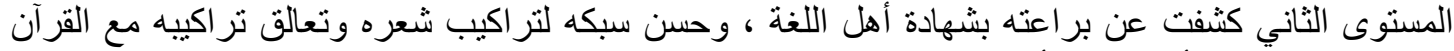
الكريم، ولم تخرج الأخبار التي أوردها الثنالبي عن موضو عين هما : قبح المطالع وحسن القصيدة. 


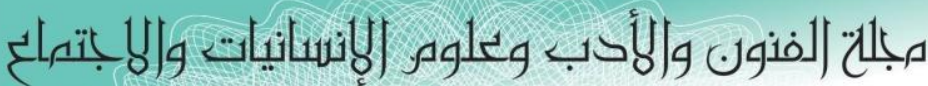

Journal of Arts, Literature, Humanities and Social Sciences

ISSN online: 2414 - 3383

ISSN print: 2616 - 3810

\section{العدد (43) ايلول - سبتمبر 2019}

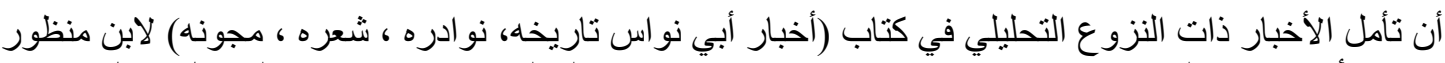

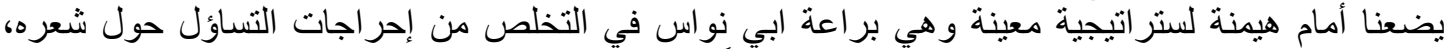

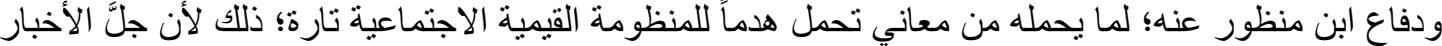
التحليلية اعتمدت على شخص أبي نو اس نفسه في تطوير بنية الحدث داخل الخبر.

ون ذللك الخبر الذي يُنادم فيه أبو نو اس الأمين حين ركب معه في سفينته (حر اقة الآلّين) فاندهش من جمالها ، و أنشد قصيدة يقول في مطلعها:

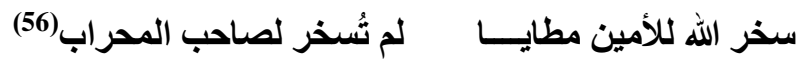

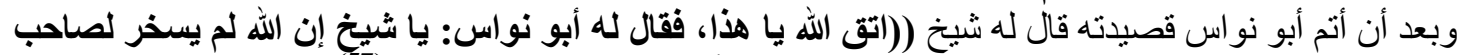

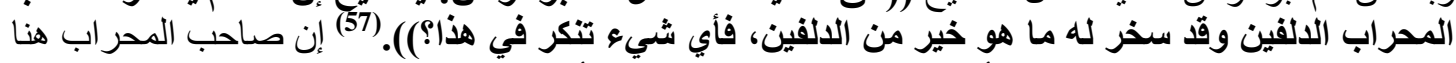

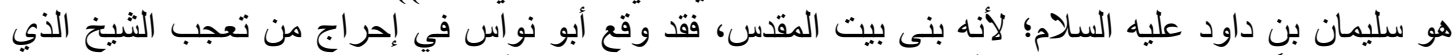

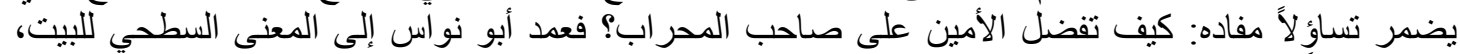

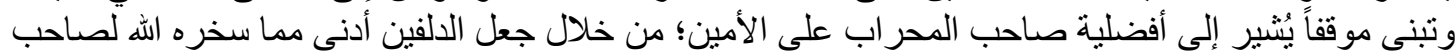
المحر اب. ويظهر النقد التحليلي المتكئ على شخص أبي نواس في تطوير بنية الخبر، ودفع عجلة أحداثه إلى الأمام في

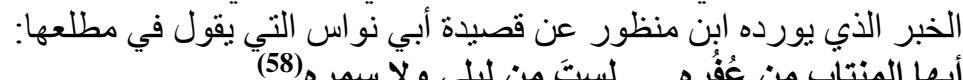

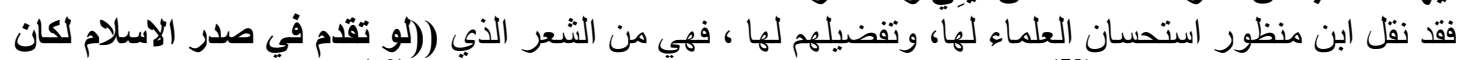

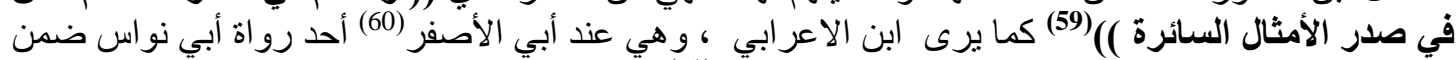

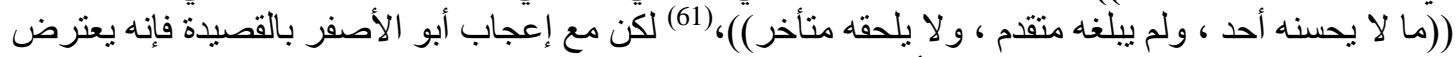

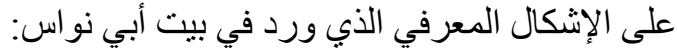

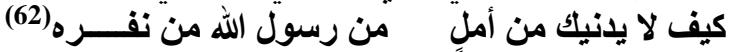

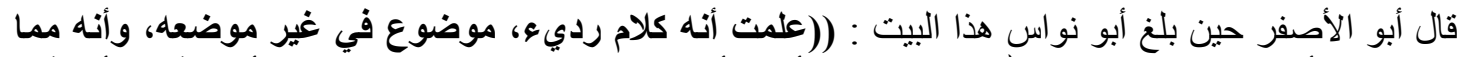

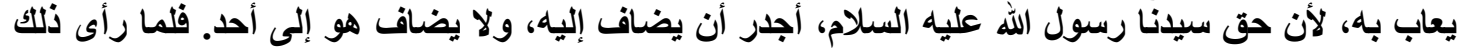

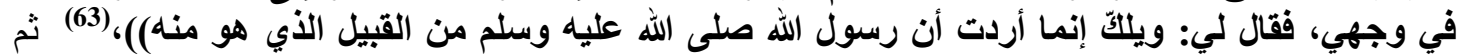
استشهد ابو نو اس بقول حسان في اللغة ذاتها:

(64)

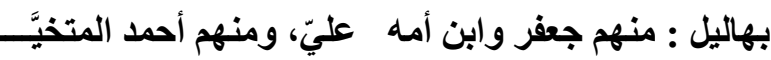

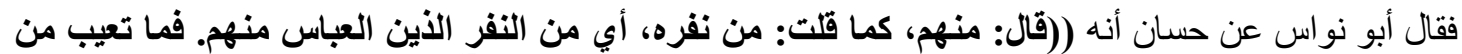

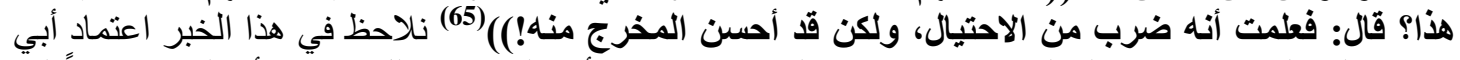

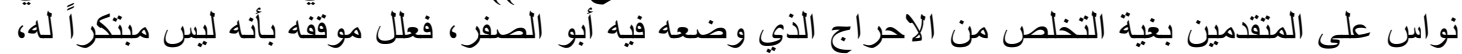

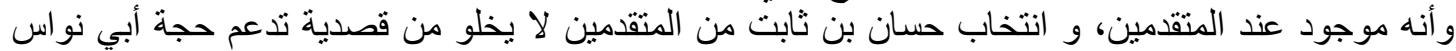

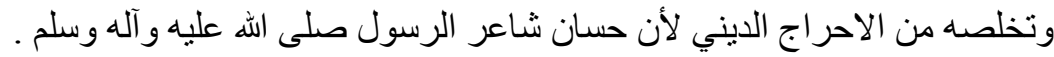


مبلحت (لفنون والأدب وتلوه الإنسانيات والبنتهماع

Journal of Arts, Literature, Humanities and Social Sciences

ISSN online: 2414 - 3383

ISSN print: 2616 - 3810

\section{العدد (43) ايلول -سبتمبر 2019}

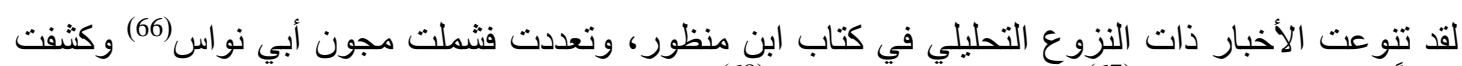

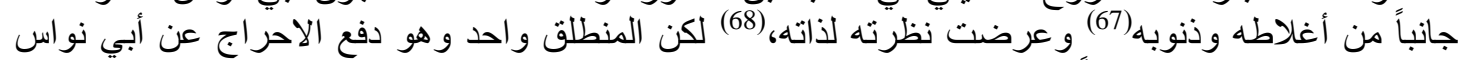

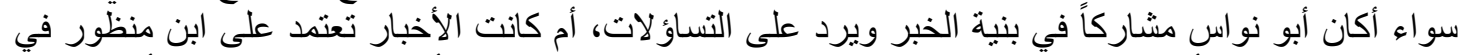

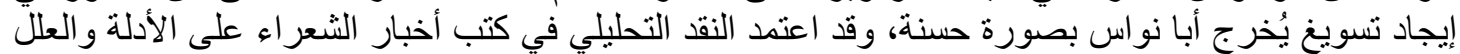
التي تعضد صحة الحكم، وتدافع عنها.

وختاماً يمكن القول أن الأحكام النقدية التي تناثرت في مدونات أخبار الثُعراء كثنفت عن جانب نقدي سواء أكان

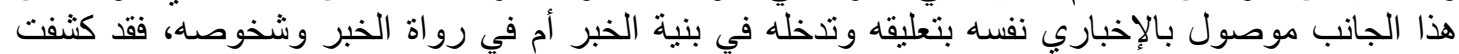

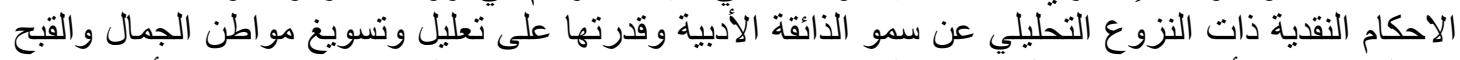

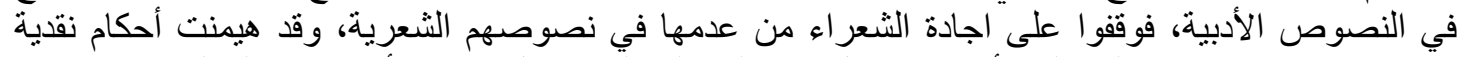

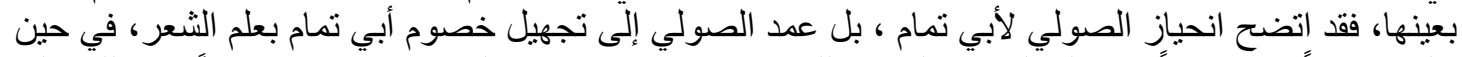

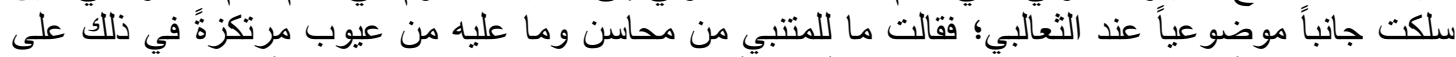

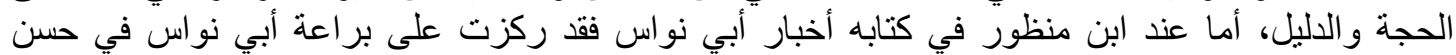

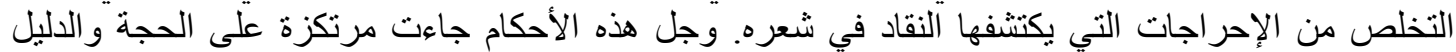
العقلي تارة و النقلي تارة أخرى، في تسويغ وتبرير المعنى الذي يميل إليه الناقد أو الاخباري.

\section{الهوامش}

(1) بنظر : قضايا النقد الأدبي بين القديم والحديث، محدد زكي عشماوي، دار النهضة العربية للطباعة والنشر،

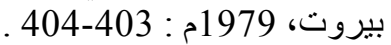

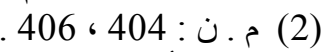

(3) ينظر : أخبار السيد الحميري : 152.

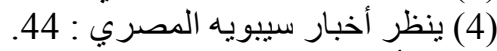

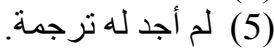

(6) ينظر : ديوان أبي تمام بشرح التبريزي: 434/4 ـ/ ورد في الديوان لفظ (فِلق) بدلاً عن (زيم) في البيت الأول.

(7) أخبار أبي تمام : 68 - 69 - 69.

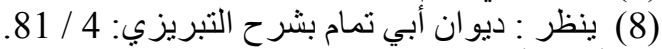

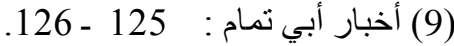

127 - 126 : 126 : (10)

(11) م. ن : 128 ـ 129 / لم أجد مقولة الإمام علي عليه السلام في نهج البلاغة.

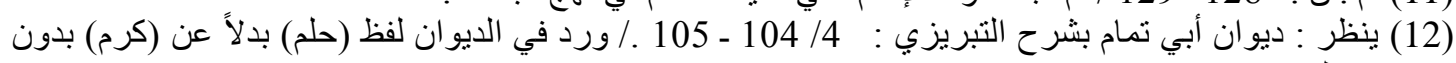

تعليق.

(13)

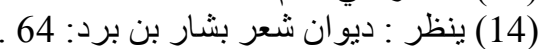

(15) أخبار أبي تمام : 129 : 129.

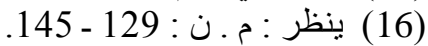

(18) (17) أخبار البحتري : 106 :

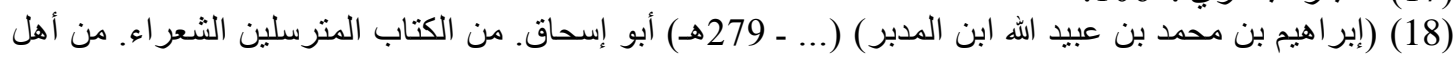

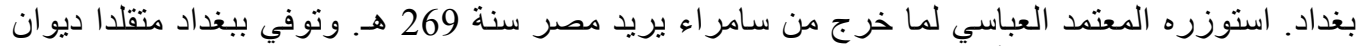

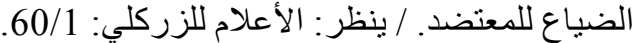

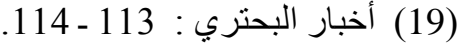

(20) بنظر : يوان البحتري : 289. 


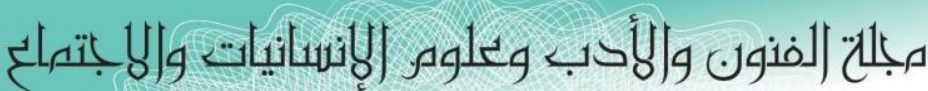

Journal of Arts, Literature, Humanities and Social Sciences

ISSN online: 2414 - 3383

ISSN print: 2616 - 3810

\section{العدد (43) ايلول - سبتهبر 2019}

(21) (علي بن الجهم بن بدر) : ( ... - 249هـ) أبُوْ الحسن. رقيق الثعر ، أديب، من أهل بغداد كان معاصراً لأبي

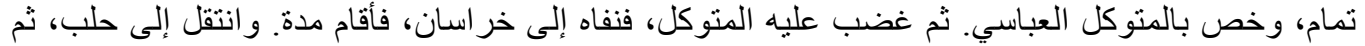

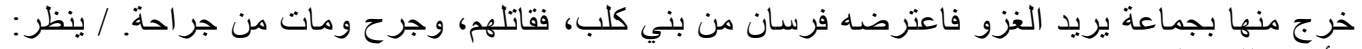

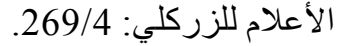

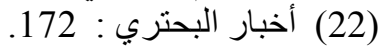

(23)

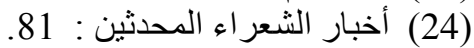

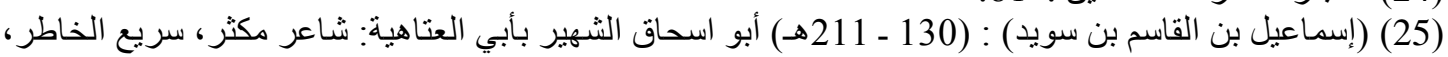

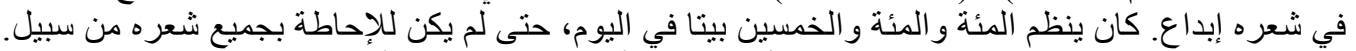

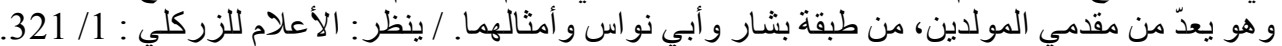

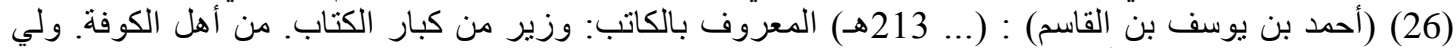

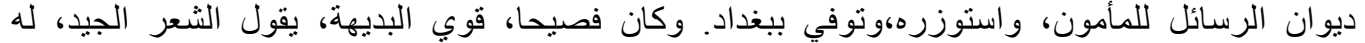

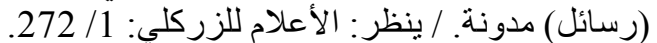

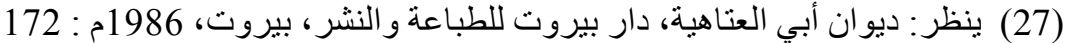

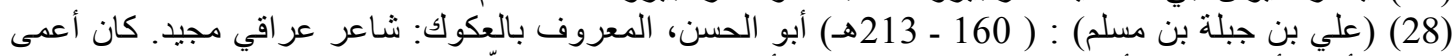

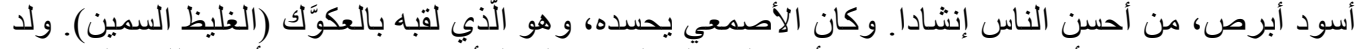

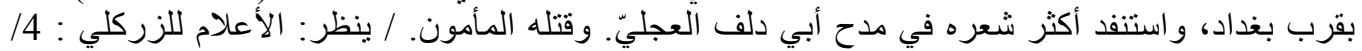

268

(29) أخبار الشعر اء المحدثين : 213.

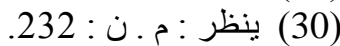

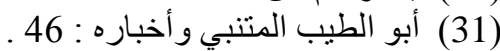

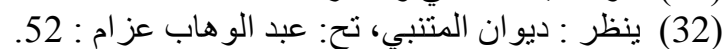

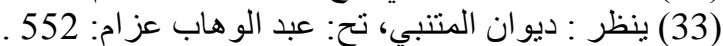

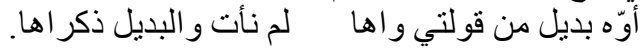

(34) أبو الطيب المتنبي وأخباره : 46 (35)

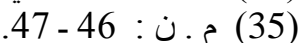

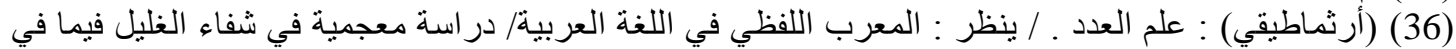

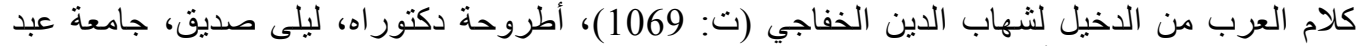

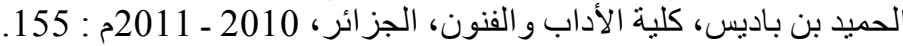

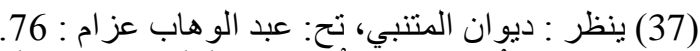

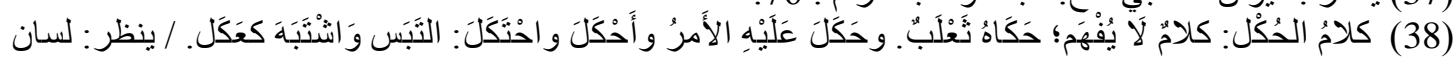

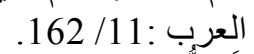

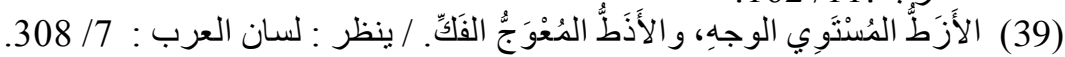

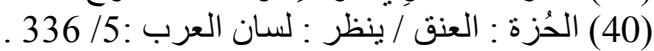

(41) أبو الطيب المتنبي و أخباره :

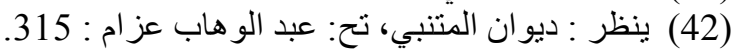

(43) أبو الطيب المتنبي وأخباره :

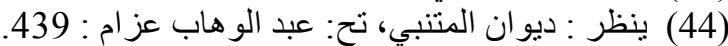

(45) أبو الطيب المنتبي وأخباره :

(46) ينظر : سر الفصاحة، ابن سنان الخفاجي (ت: 466هـ)، دار الكتب العلمية، ط1، بيروت، 1982م: 183/1 .

(47) أبو الطيب المتنبي و أخباره : 47 : 47 :

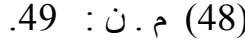

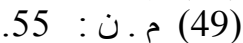

(50) ينظر : ديو ان المتنبي، تح: عبد الوهاب عز ام : 314. 


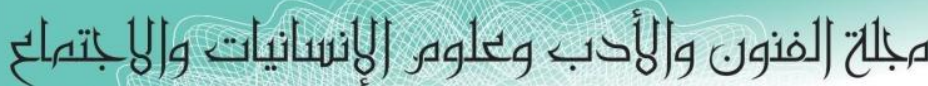

Journal of Arts, Literature, Humanities and Social Sciences

ISSN online: 2414 - 3383

ISSN print: 2616 - 3810

\section{العدد (43) ايلول - سبتمبر 2019}

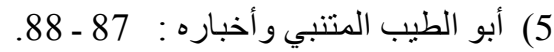

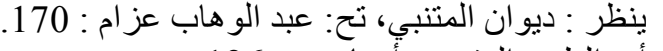

$$
\begin{aligned}
& \text { أبو الطيب المتنبي و أخباره : } 126 \\
& 126 \text { : الطب } 153
\end{aligned}
$$

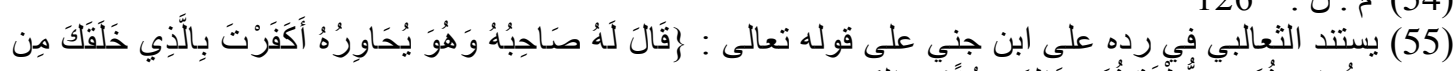

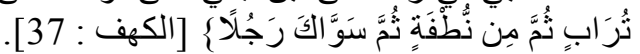

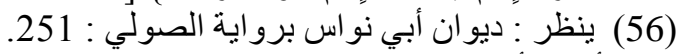

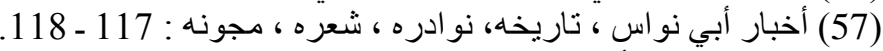

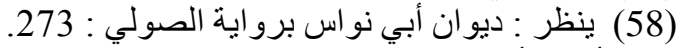

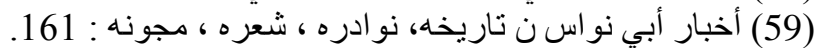

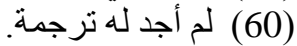

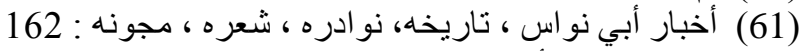

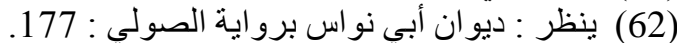

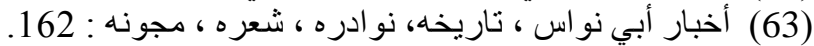

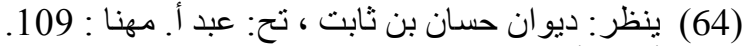

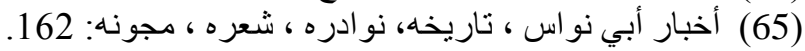

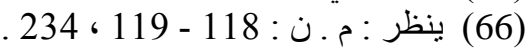

(67)

208 (68) بنظر : م.ن : 207)

1 أمصادر الطبب المتنبي وأخباره، أبو منصور عبد الملك الثعالبي النيسابوري،(ت: 429هـ)، مطبعة التوفيق

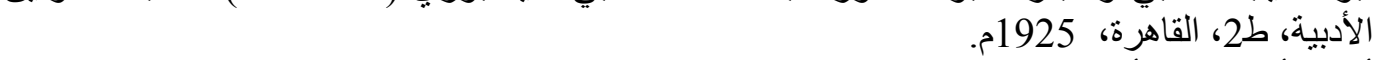

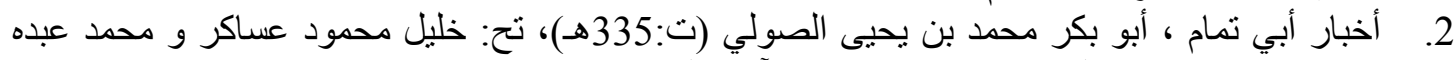

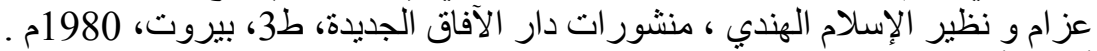

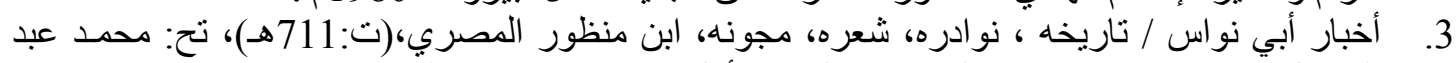

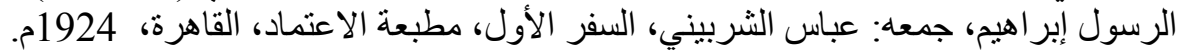

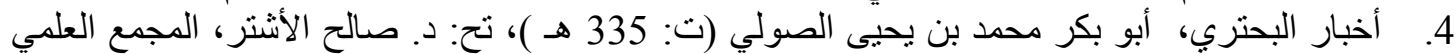

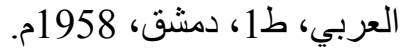

5. أخبار السيد الحميرب، أبو عبد الله محمد بن عمران المرزباني الخراساني (ت: 384 هـ)، تح: محمد هادي

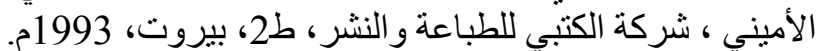

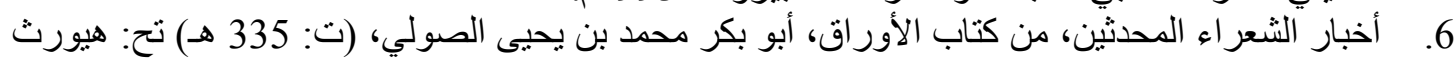

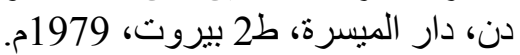

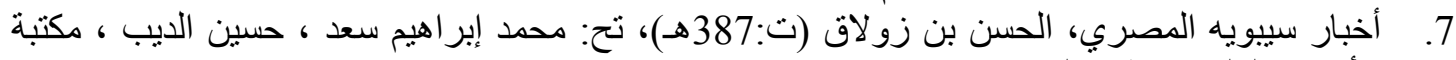

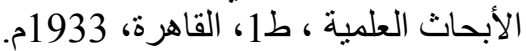

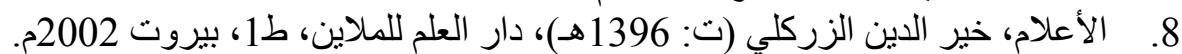

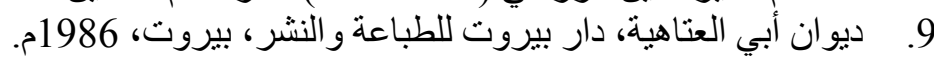

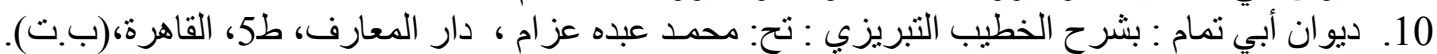

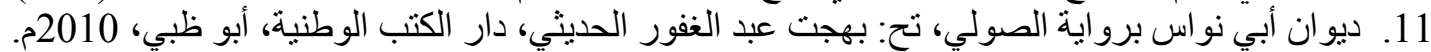

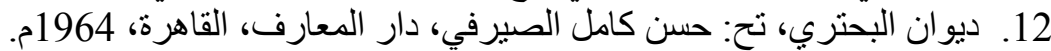

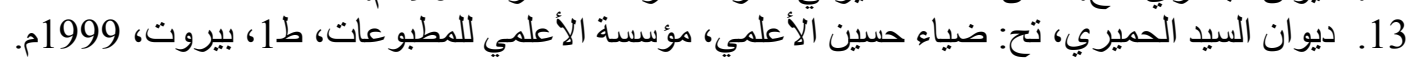



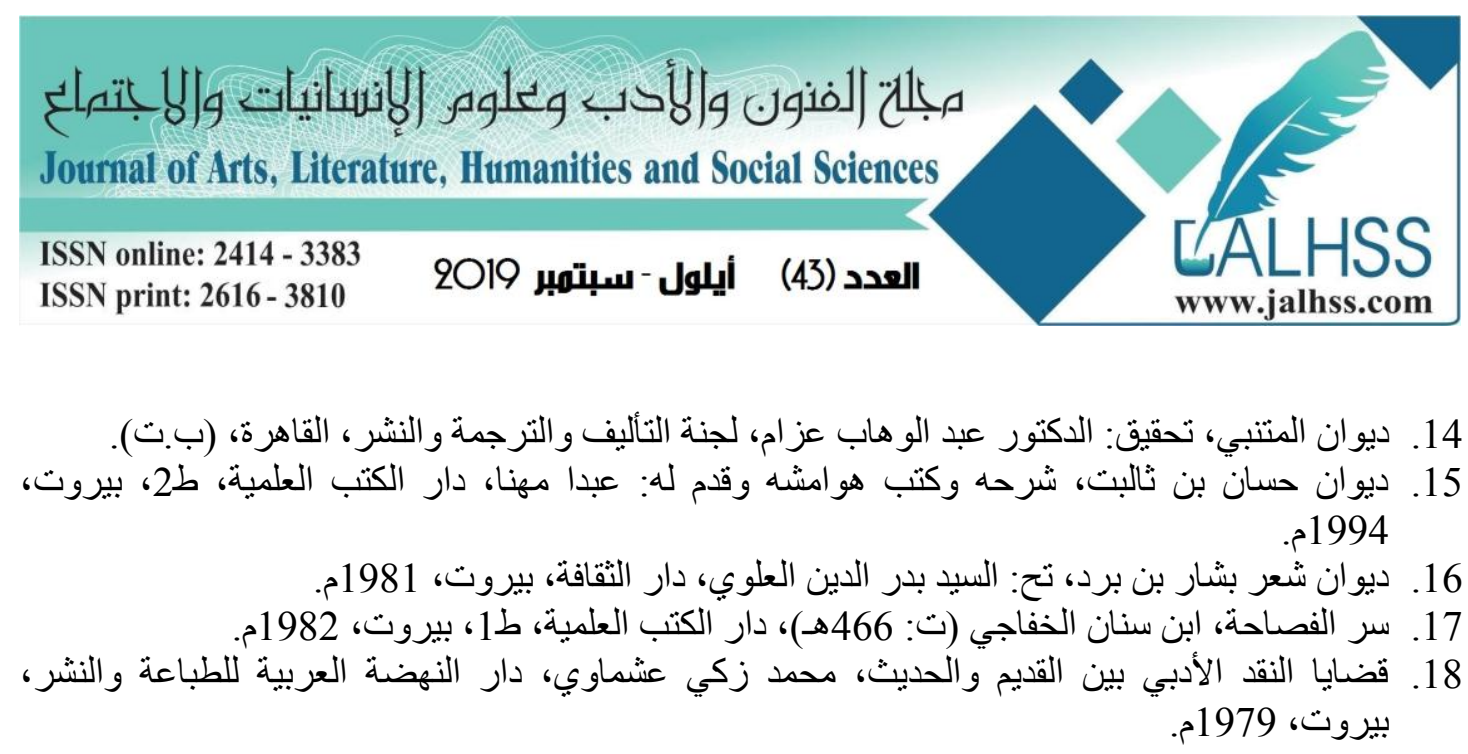

\section{References}

1. Abu Tayeb al-Mutanabbi and his news, Abu Mansour Abdul Malik al-Tha'labi Alnisaburi, (Tel: 429 e), Press Tawfiq literary, 2nd edition, Cairo, 1925.

2. News of Abu Tammam, Abu Bakr Mohammed bin Yahya al-Souli (Tel: 335 e), under: Khalil Mahmoud Asaker and Mohammed Abdo Azzam and the counterpart of Indian Islam, publications House of New Horizons, i 3, Beirut, 1980.

3. Abu Nawas news / history, anecdotes, poetry, Majouna, Ibn Manzoor al-Masri, (Tel: 711 e), under: Mohamed Abdel Rasoul Ibrahim, collected: Abbas El-Sherbini, the first travel, Al-Etimad Press, Cairo, 1924.

4. News Al-Bohtari, Abu Bakr Mohammed bin Yahya al-Souli (Tel: 335 e), under: d. Saleh Al-Ashtar, Arab Scientific Complex, 1st Floor, Damascus, 1958.

5. News Mr. Al-Humairi, Abu Abdullah Mohammed bin Omran Marzabani Khorasani (Tel: 384 e), under: Mohammed Hadi Al-Amini, Al-Ketbi Company for Printing and Publishing, 2nd floor, Beirut, 1993.

6. News of modern poets, from the book of papers, Abu Bakr Mohammed bin Yahya al-Sule, (Tel: 335 e) Open: Hayworth Dunn, House soft, I 2 Beirut, 1979.

7. News Sibawayh Egyptian, Hassan bin Zulak (Tel: 387 e), Open: Mohammed Ibrahim Saad, Hussein El Deeb, Scientific Research Library, i 1, Cairo, 1933.

8. Flags, Khair al-Din al-Zarkali (Tel: 1396 e), Dar al-Alam for the lane, I 1, Beirut 2002.

9. Diwan of Abu al-Ataheya, Beirut House for Printing and Publishing, Beirut, 1986.

10. Office of Abu Tammam: Explain Khatib Tabrizi: Under: Mohammed Abdo Azzam, Dar al-Maarif, i 5, Cairo, (b).

11. Diwan Abu Nawas novel Sule, under: Bahjat Abdul Ghafour Hadithi, the National Library, Abu Dhabi, 2010.

12. Diwan Al-Buhtari, under: Hassan Kamel Al-Serafi, Dar Al-Maaref, Cairo, 1964.

13. Court of Sayyed Al-Humairi, under: Dia Hussein Al-Alami, Al-Alami Foundation for Publications, I 1, Beirut, 1999. 


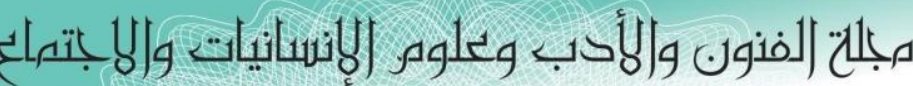

Journal of Arts, Literature, Humanities and Social Sciences

ISSN online: 2414 - 3383

ISSN print: 2616 - 3810

العدد (43) ايلول - سبتمبر 2019

14. Diwan al-Mutanabbi, investigation: Dr. Abdul Wahab Azzam, Committee of authoring, translation and publication, Cairo, (b).

15. Diwan Hassan bin Thalbet, his explanation and wrote margins and presented to him: a slave Muhanna, House of scientific books, I 2, Beirut, 1994.

16. Diwan poetry of Bashar ibn Bard, under: Mr. Badr Eddin Alaoui, House of Culture, Beirut, 1981.

17. The Sacrament of Eloquence, Ibn Sinan Al-Khafaji (Tel: 466), Scientific Books House, 1st Floor, Beirut, 1982.

18. Issues of literary criticism between ancient and modern, Mohammed Zaki Ashmawi, the Arab Renaissance House for Printing and Publishing, Beirut, 1979. 